\title{
WCSC 2016: the 6th World Chess Software Championship
}

Article

Accepted Version

Krabbenbos, J., van den Herik, J. and Haworth, G. (2017) WCSC 2016: the 6th World Chess Software Championship. ICGA Journal, 39 (2). pp. 151-159. ISSN 1389-6911 doi: https://doi.org/10.3233/ICG-170013 Available at https://centaur.reading.ac.uk/67923/

It is advisable to refer to the publisher's version if you intend to cite from the work. See Guidance on citing.

Published version at: http://content.iospress.com/articles/icga-journal/icg 0013

To link to this article DOI: http://dx.doi.org/10.3233/ICG-170013

Publisher: The International Computer Games Association

All outputs in CentAUR are protected by Intellectual Property Rights law, including copyright law. Copyright and IPR is retained by the creators or other copyright holders. Terms and conditions for use of this material are defined in the End User Agreement.

\section{www.reading.ac.uk/centaur}

\section{CentAUR}

Central Archive at the University of Reading

Reading's research outputs online 


\section{WCSC 2016: the $6^{\text {th }}$ World Chess Software Championship}

Jan Krabbenbos ${ }^{\mathrm{a}}$, Jaap van den Herik ${ }^{\mathrm{b}}$ and Guy Haworth ${ }^{\mathrm{c}, 1}$

${ }^{a}$ Amersfoort, The Netherlands

${ }^{b}$ Faculties of Law and Science, Leiden University, Leiden, The Netherlands

${ }^{c}$ University of Reading, Reading, UK

The $6^{\text {th }}$ World Chess Software Championship started on July $2^{\text {nd }}, 2016$. Seven programs as in Table 1 participated in a round robin tournament of seven rounds. The tournament took place at Leiden University and was organized by the ICGA, LIACS and LCDS. The sponsors were Google, Naturalis Biodiversity Center, the municipality of Leiden, Leiden University, its Faculty of Science, the ICGA, iSSC, SurfSara, Digital Game Technology and NWO Exact Sciences. It was held in conjunction with the $22^{\text {nd }}$ World Computer Chess Championship, the $19^{\text {th }}$ Computer Olympiad and the $9^{\text {th }}$ Computers and Games conference.

The six WCCC contestants (Krabbenbos et al, 2017a) were joined by Richard Pijl's THE BARON (CPW, $2017 \mathrm{a} / \mathrm{b}$ ), see Table 1. The standard platform, used by all seven programs, was an Intel I7-3770 with four cores running at the Base Frequency of $3.40 \mathrm{GHz}$ and providing eight threads if hyperthreading was invoked. The game tempo was $45^{\prime}+5^{\prime \prime} /$ move for both sides.

Table 1

The participants in WCSC 2016

\begin{tabular}{|c|c|c|c|c|}
\hline$\#$ & Program & Author(s) & Country & Operator \\
\hline 1 & GINKGO & $\begin{array}{c}\text { Frank Schneider, Kai Himstedt and } \\
\text { Robert Hyatt }\end{array}$ & $\mathrm{DE}$ & Timo Haupt, Kai Himstedt \\
\hline 2 & HIARCS & Mark Uniacke & GB & Harvey Williamson, Hans v.d. Zijden \\
\hline 3 & JONNY & Johannes Zwanzger & $\mathrm{DE}$ & Johannes Zwanzger \\
\hline 4 & KOMODO & $\begin{array}{c}\text { Don Dailey, Larry Kaufman \& Mark } \\
\text { Lefler }\end{array}$ & USA & Mark Lefler \& Erdogen Günes \\
\hline 5 & RAPTOR & Steve Webber & USA & Wolfgang Zugrav \\
\hline 6 & SHREDDER & Stefan Meyer-Kahlen & $\mathrm{DE}$ & Stefan Meyer-Kahlen \\
\hline 7 & THE BARON & Richard Pijl & NED & Richard Pijl \\
\hline
\end{tabular}

Round 1: GINKGO - RAPTOR 0-1 (D47), KOMODO - HIARCS 1/2-1/2 (A32) and SHREDDER - JONNY 1/2-1/2 (D45).

GINKGO versus RAPTOR proved that computers know many things and can compute even more. The opponents played a Semi Slav opening in which Black castled to the queenside and the center was dominated by dynamic pieces and pawns. Both programs knew that there were many previous games in their libraries. At move 22 White played the novelty $\mathbf{2 2}$. Nb5 whereas 22. Ne4 and 22. Na4 had been played before. Apparently the attacked knight was a problem to White. This observation was very well

\footnotetext{
${ }^{1}$ Corresponding author: Guy Haworth, guy.haworth@ bnc.oxon.org
} 
exploited by RAPTOR. In the position of Figure 1a, it played $\mathbf{2 8} . . . \mathbf{R b} 7$ and this move hit the nail on the head. Where should the white knight go and what should be the result? It turned out that there was no better option than 29. Na7 and after 29. ... Qb6 the queens were exchanged. However White's knight problem was not solved and it took several moves to free it. Black spent that time quite well and built up a won position. Although White had the pair of bishops against two knights, it turned out that the two passed pawns supported by the knight were sufficient for the win. On move 47 White agreed with this opinion by sacrificing the exchange in an attempt to prolong the game. RAPTOR completed the work efficiently and effectively.

The new world champion KOMODO had a tough game against HIARCS in the first round of the WCSC. After an English opening we saw that White's position had to withstand some pressure from the black pieces. With the move 18. ... Bf5, Black made an attempt to maximize its pressure with a variety of small threats. It was time for White to take appropriate actions. KOMODO did so with 19. Be4, see Figure $1 \mathrm{~b}$. Surprisingly this move indeed solved all the problems White was facing. After an extended sequence of piece exchanges the position was equal. Both sides tried to prove that their side was slightly better but it was in vain and the draw could not be avoided.
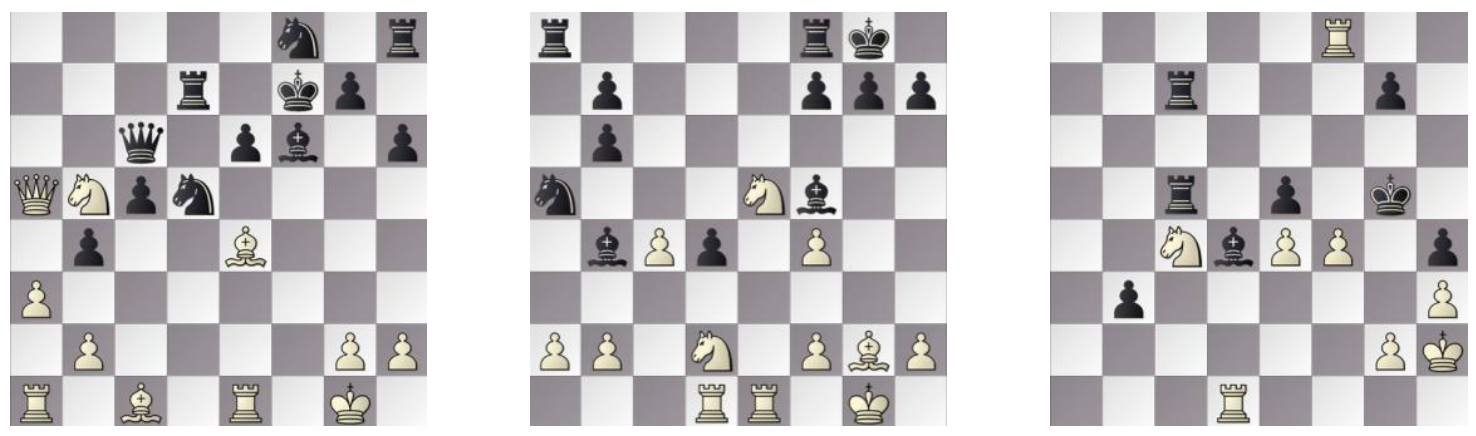

Fig. 1. R1: a) GINKGO - RAPTOR 28b, b) KOMODO - HiARCS 19w and c) SHREDDER - JONNY 58b.

The game SHREDDER - JONNY was a fantastic fight. After a declined Queen's Gambit White tried to consolidate a small opening advantage. But JONNY also aimed at advantage and we saw a long and highly focused fight. It looked like Black was the cleverer collector of small advantages. JONNY obtained some pressure on the White position. However SHREDDER understood the possibilities of the position quite well and succeeded time and again in replying adequately to the small threats posed by JONNY. The position of Figure $1 \mathrm{c}$ is a telling example. White has just played $\mathbf{f} \mathbf{4}$ and there followed a long sequence of moves after which the outcome was a clearly drawish position with few pieces. However these players are both fighters to the very end. Those who would like to see the game in its full extent will have to replay some forty more moves in which the value of the game does not change. The draw was a deserved result for both sides.

Round 2: HIARCS - SHREDDER 0-1 (B48), RAPTOR - KOMODO 0-1 (B10) and THE BARON - GINKGO 0-1 (C17).

The second round of the WCSC was remarkable as all three games ended in a win for Black. The first one was between HIARCS and SHREDDER. They started with a sharp variation of the Sicilian Defense in which both sides had a pawn run on the opponent king. Essentially, the issue was who would be the first to bring the opponent king into danger. This game was an exception because both players seemed to be the first to do so. The position of Figure 2a is an indication of what was at stake. Black and white pawns intermingle 
in the front of both the white and black kings. It was hard to get a correct evaluation although the expert opinion may be somewhat inclined towards Black since with hindsight we know that Black won the game. The illustrated position seems to be a win for one side or the other rather than a draw. However this opinion disregards the defending power that current programs possess. They have ingenuity and find escapes time and again. That also happened in this game where White was able to reach an endgame of rook and bishop versus a queen with three pawns on both sides. Black played the position very well and won deservedly.
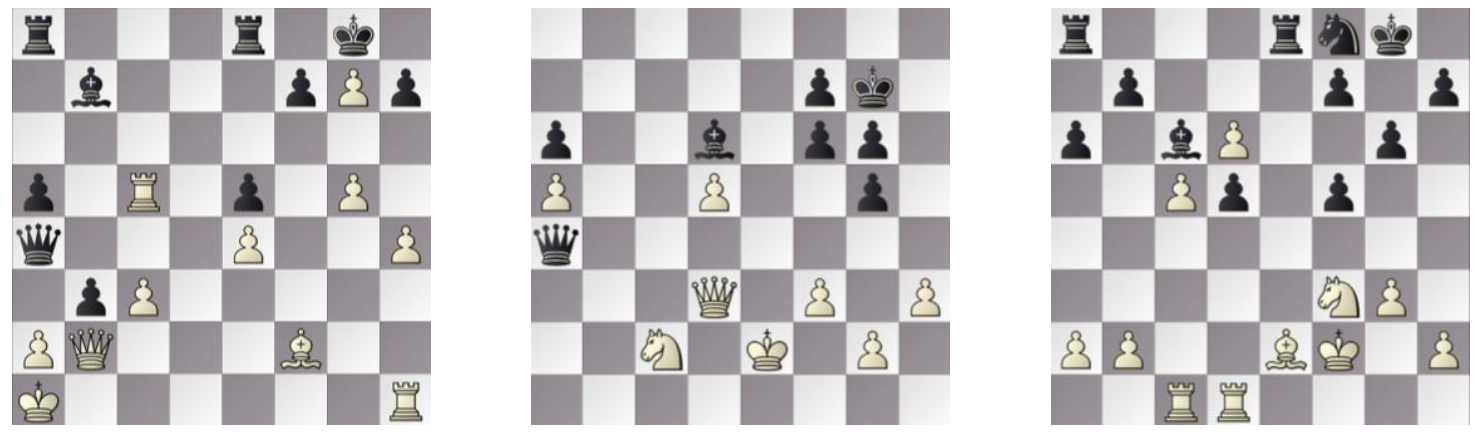

Fig. 2. R2: a) HiARCS - SHREDDER 28b, b) RAPTOR - KOMODO 67w and c) THE BARON - GinKGO 23w.

The game RAPTOR - KOMODO can be characterized as weaker player against world champion. This is a well-known scenario in the human chess world. World champion Karpov was a chess player pur sang. He did not like analysis: he liked to play. If he discussed a game afterwards and his opponent stated that the current position was objectively seen as a draw he always invited the player with the words "Ok, you think so, but let us play and see what happens." This is the best characterization of the game RAPTOR - KOMODO. In the early middlegame RAPTOR occasionally lost a tempo which KOMODO exploited to its advantage but this was not sufficient to reach a winning position. After a long fight, KOMODO did not have an unequal ending on the board. However, equality or not, KOMODO pressed on and outplayed RAPTOR just as Karpov did with many of his opponents. By the position of Figure $2 b$, its persistent play had resulted in the winning of the a-pawn. The conclusion was unavoidable: the strongest program won this match and it was KOMODO.

In the game THE BARON - GINKGO, White started ambitiously and obtained a passed pawn on d6. Was it an asset or was it a liability? If it was a liability could it be made an asset? White worked very hard to answer these questions positively. It sacrificed a pawn on $\mathrm{f} 5$ and really obtained a nice looking position. Now the question was how to exploit this position. On move 23, see Figure 2c, there was a decisive moment. White chose 23. Rd3 but 23. b4 would have been better, or even 23. a3 aiming to answer 23... a5 with 24. b4. With this opportunity missed, Black was able to take the initiative in the complex position and slowly achieved the upper hand. That resulted in a deserved win for GINKGO.

Round 3: KOMODO - THE BARON 1-0 (A28), SHREDDER - RAPTOR 1-0 (D19) and JONNY - HIARCS 0-1 (D45).

In the game KOMODO - THE BARON we saw an English four knights opening which always requires subtle treatment. Both sides are more or less at liberty to place their pieces on the appropriate squares. The best strategists have the best winning chances. In the game KOMODO showed its power. Nevertheless THE BARON developed some nice ideas and handled the game accordingly. It looked like nothing was wrong with its approach although its pieces were not fully harmonised. However next to strategy, tactics play an important role in chess. In the position of Figure 3a, KOMODO found a surprising move in 28. Rxg6, one 
worthy of being played by the world champion. It completely destroyed the Black position. In the sequel Black could have defended better, e.g., by playing 29. .. Bxf5 instead of 29. ... Rxf5, but this would not have prevented the deserved win by White.
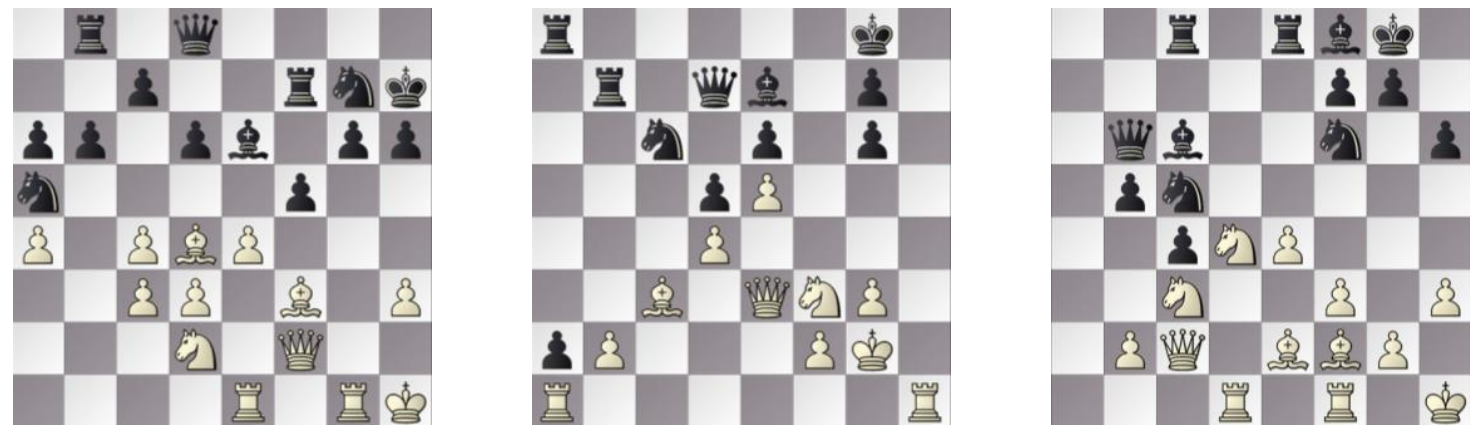

Fig. 3. R3: a) KOMOdO - THe BARON 28w, b) SHREDDER - RAPTOR 28w and c) JonNy - HiARCs 25w.

SHREDDER - RAPTOR was an exciting game that started as a Slav defense, Dutch variation. SHREDDER played rather actively from the opening and it looked like it had a clear initiative in hand. However Black found a very good defense which was based on the activity of its a-pawn. By its sharp play Black challenged SHREDDER to move into immediate action. The two different approaches are seen in the position of Figure 3b: Black has a dangerous pawn on a 2 and White has chances along the h-file. The question now is who is first and what is more important, to catch the black king or to promote the black pawn to a queen? White played very accurately and, in the position of Figure 3b, played 28. Rh2. Black managed to avoid being mated but had to restructure its defensive position. Still it had its asset on a2. White was well aware of this painful pressure point, regrouped its pieces to eliminate the a-pawn and did so in a very elegant way. On move 45 it simply took the pawn with its rook although its queen was attacked by Black. The implicit exchange of queens eliminated Black's chances completely. White won by following the better concepts during the game.

In the WCSC, the JONNY - HIARCS game was played under different 'common platform' circumstances from those of the WCCC: JONNY was therefore handicapped by having 2396 cores fewer. With only 4 cores it is still a strong program as can be seen in this game even though it lost. The game started as a Queen's Gambit Declined. Black played forcefully but JONNY showed its experience and held its own. Yet the initiative was with Black. In the position of Figure 3c, JONNY took the wrong decision, playing 25. b4? The idea was based on the cunning move 27. Rb1 which the program rated as better than was realistic. A better choice would have been 25. Nxc6. The game progressed with Black increasing its threats and opportunities. On move 37, White had no other choice than to sacrifice a pawn and hope that the resultant ending would be defendable. It turned out not to be the case and so HIARCS added a nice victory over the former world champion to its credentials.

Standings: 1=. KomOdO, ShredDER 21/2; 3. Hiarcs 11/2; 4=. GinKGO, RAPTOR 1; 6. JONNY 1/2; 7. THE BARON 0.

Round 4: RAPTOR - JONNY 0-1 (D00), THE BARON - SHREDDER 1/2-1/2 (B47) and GINKGO - KOMODO 01 (A88).

In the game RAPTOR - JONNY, RAPTOR did not show any respect for the former world champion. Right from the beginning RAPTOR played a fresh game with fresh ideas and with great energy. The game is too 
complex to analyze in this report in detail. Obviously White had much compensation for the pawn sacrificed. Having compensation is one thing but capitalizing on it is another, in this case, a challenging task which White could not execute. The position of Figure $4 \mathrm{a}$ is a telling example of White taking the wrong path. Black had just played 25. ... Rf5 with the threat Rh5. Obviously the position is complex. A possible 26. gxf3 does not solve all problems but actually seems to be playable. However White played the wrong move with 26. Qa4. In itself the move is understandable but seen from a strategic viewpoint White should never have moved the queen from the kingside where the fight was taking place. After this move, White's chances disappeared. Nevertheless, White reached an endgame in which Black had to work hard for its ultimate win.
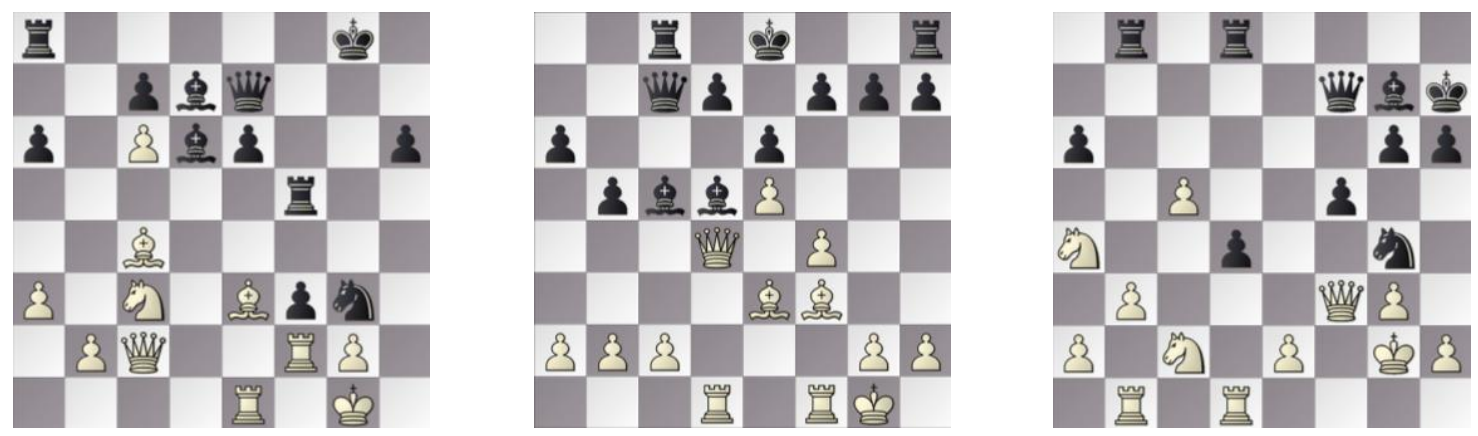

Fig. 4. R4: a) RAPTOR - JONNY 26w, b) THE BARON - SHREDDER 15w and c) GINKGO - KOMODO 31w.

SHREDDER is a former world champion and thus has proven strength at its disposal. Even while SHREDDER played at its best, THE BARON was a runner-up: strong and dangerous for any opponent. In this new encounter THE BARON showed how easy it is to make a draw with one of the strongest programs. The simple trick is to exchange all pieces to reach an elementary and drawn ending. This strategy succeeded in the current game. Consider Figure 4b and understand that Qxc5 reaches the result described above.

The game GINKGO - KOMODO started as a Dutch game, Leningrad variation. This is a difficult opening, very strategic and full of pitfalls. For GINKGO it was a chance to face KOMODO on its strongest point, namely strategy. GINKGO did well in the opening phase and also in the early middlegame. It was difficult for KOMODO to get to grips with the white position. Black tried several things but White always had an adequate answer, at least up to move 31, see Figure 4c. Then GINKGO faced a choice between $31 . \mathrm{Kg} 1$ and 31. Kh1. For human beings both had their advantages and disadvantages. For computers, matters should be clearer as $31 . \mathrm{Kg} 1$ is in fact highly preferable. However GINKGO played $\mathbf{3 1}$. Kh1 and was tricked into a dubious situation. The move was not a clear blunder but simply weak, suffering from all kinds of small deficiencies as shown by the manoeuvre 31... Re8, 32... Re4. White's answer 33. h3 then invited the black pieces to penetrate its position. After that move White was lost although it was some ten moves before GINKGO resigned.

Standings: 1. Komodo 31/2; 2. Shredder 3; 3=. HiarCS, Jonny 11/2; 5=. GinKGO, RaPtOR 1; 7. The BARON $1 / 2$.

Round 5: SHREDDER - GINKGO 1/2-1/2 (E11), JONNY - THE BARON 1-0 (E04) and HIARCS - RAPTOR 0-1 (A00).

In the game SHREDDER - GINKGO both programs aimed at a battle in full dress. The first ten moves went rather quietly then both sides placed their pieces on squares where they could start attack activities. White believed the time was ripe to start a direct fight with 22. Nxf5, see Figure 5a. This led to an interesting 
position after 22. ... Qxf5 23. Rxe4 Qh3. White was a pawn up but the exchange was still an element of the skewer on b7. The complications that followed were mostly in favour of Black although White could stand on its own. For one reason or another White, time and time again, found the right moves and this was the basis of its survival. Of course the game continued and several more local fights occurred, always with the same result. This implied that at least in this game the programs were each other's equal. The draw result was well deserved by both sides.
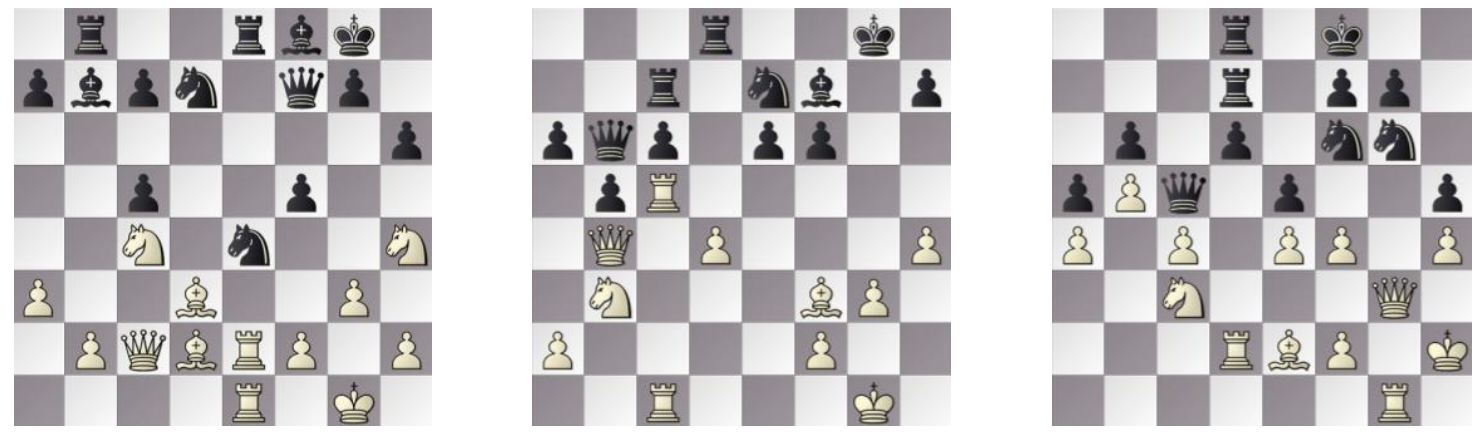

Fig. 5. R5: a) SHREDDER - GinKGo 22w, b) JONNY - THE BARON 32w and c) HiARCS - RAPTOR 40w.

JONNY - THE BARON was a game in which JONNY could show all its knowledge of chess and chess play whereas THE BARON was applauding the ideas JONNY put forward. This humble position does not make one enthusiastic for the game and prevents most of the pleasure of replaying it. Right from the beginning JONNY improved its position by nothing other than playing strong moves. On move 32 all White's pieces were perfectly placed and it was time for the decisive variation to be played. Although the square d5 was defended four times and attacked only twice in Figure 5b, White decided to play 32. d5, freeing the line to $f 4$ for the queen. The game continued 32. ... exd5 33. Qf4 Kg7 34. h5 h6 35. Nd4 Rg8 36. Bg4 Qb8 37. Re1 Rb7 38. Qc1 Kh7 39. Rxe7 after which the Black position collapsed. A nice game by JONNY.

The game HIARCS - RAPTOR had an unusual start with 1. a3: both programs were immediately out of book. This meant that they played on their own intuition. What we saw was a game in which both players showed ingenuity and experience. They arranged their pieces in a harmonious way, rearranged them and formulated new goals to achieve. Around move 40 it was time to force the opponent to make decisions. Black did so, see Figure 5c, by playing 39.... e5 and the game continued 40. f5 Nf4 41. Qxg7. Then it turned out that the black king was safe on e 7 and could later find a safe place on the queenside. Meanwhile the knight on $\mathrm{f} 4$ and the queen from $\mathrm{c} 5$ reigned over the position. Therefore White decided to sacrifice an exchange in order to reduce the power of these overarching pieces. This worked well but the deficit of the exchange proved costly. Black played very well and in an indisputable way brought the full point home.

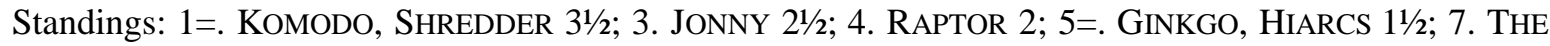
BARON $1 / 2$.

Round 6: THE BARON - HIARCS 1/2-1/2 (B18), GINKGO - JONNY 1/2-1/2 (A01) and KOMODO - SHREDDER 1-0 (B23).

THE BARON knows very well that, when playing an opponent with a greater reputation, showing activity is important. In chess this is possible by not being aggressive but being determined in difficult positions. This playing style is what THE BARON showed in its game against HIARCS. In the opening, a Caro-Kann, both players found their way along the usual paths and then started to go their own way. HIARCS seemed 
to have the initiative but THE BARON was inventive and created counterplay on the kingside and in the centre. HIARCS had to handle new ideas and insert them in its own plans, a complicated task. An example of such a task is given in Figure 6a where HIARCS has a good position. For THE BARON it was time to become active. So it played the natural move 35. $\mathbf{d 5}$ and saw that HIARCS had difficulties in resolving the complications. The game continued 35. ... cxd5 36. cxd5 Kg7 37. b3 a5 38. d6 Ref7 39. Re4 and again we were in a position where it was difficult to find the right way. Both programs did so and a little bit later the game was drawn. Our thanks for two elegant performances.
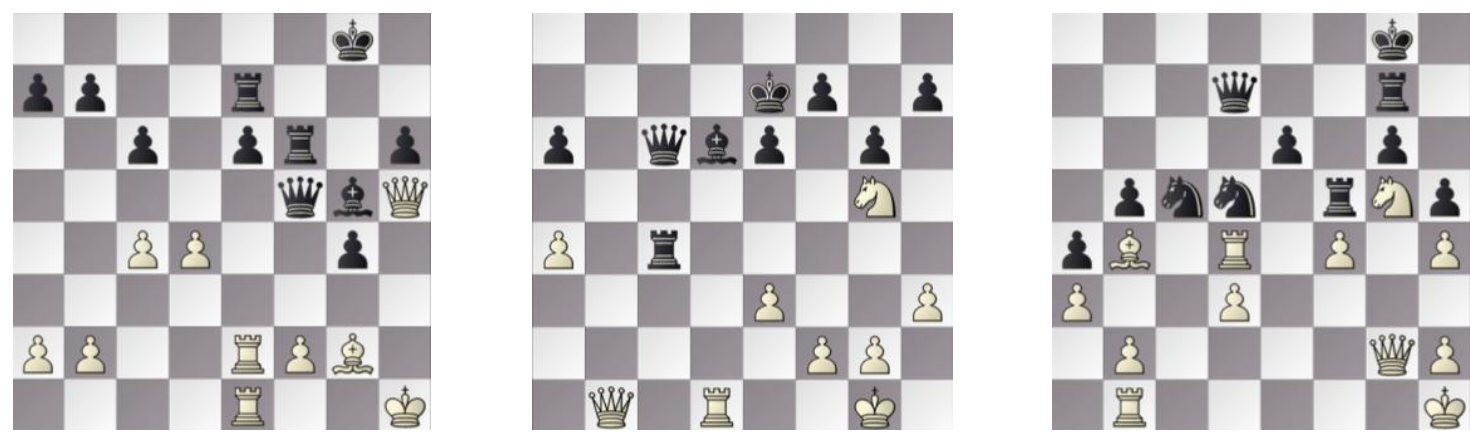

Fig. 6. R6: a) THE BARON - Hiarcs 35w, b) GinKGO - JonNy 26w and c) KOMODO - SHREDDER $37 b$.

The game GINKGO - JONNY started with $\mathbf{1 . b 3}$ for which there is not much opening theory. Yet the players built up acceptable positions on both sides. Here again we saw that JONNY was severely handicapped by the use of only four cores. The game progressed in a quiet way with some difficult decisions to be made. In Figure 6b, we show the result of a decision made earlier in the game tree search. It deals with the capturing of $\mathrm{h} 7$ by White and $\mathrm{a} 4$ by Black. Apparently both programs considered it a fair pawn exchange. However the result is that Black has a passed pawn and White a knight which is for some time out of play. Nevertheless Black was unable to exploit this situation in its favour. Eventually the game reached another difficult decision point which was solved in the same way so there was no surprise when the final result of the game was a draw.

In a closed Sicilian game KoMODO and SHREDDER were fighting for first place in the tournament. From the beginning Black tried to keep the initiative. That was a good idea but the result was that Black had two holes in its fortress, one on 95 and one on e5. The hole on g5 was occupied by a white knight on move 20, that on e 5 by a white knight on move 40 . Although they were strategic drawbacks, Black could live with them. However a most unsuitable decision by Black was 37... Nb3, see Figure 6c. It was the beginning of play without the knight and as the game went on White, KOMODO, was effectively playing with a knight ahead. In summary, with that knight advantage and two holes to enter Black's position, White was expected to win the game. Black made two attempts to change the course of events, the first being $\mathbf{5 4}$. Na1 and the second 64. Nc1. Both attempts were in vain and White duly won the game. With this win, KomODO ensured that it was the winner of the software tournament with one round to spare as SHREDDER had no more games to play.

Standings: 1. KOMODO 41/2; 2. SHREDDER 31/2; 3. JONNY 3; 4=. GinKGO, HiARCS, RAPTOR 2; 7. THE BARON 1 . 
Round 7: JONNY - KOMODO 1/2-1/2 (D43), HIARCS - GINKGO 1/2-1/2 (E06) and RAPTOR - THE BARON 1-0 (C65).

JONNY - KOMODO ended in a draw. It was certainly not typical of a human 'grandmaster draw', short and effectively uncontested. It was a grandmaster draw in the world of computer players, exciting play inspiring ideas and materially unbalanced positions. All positions are difficult to evaluate in isolation. When witnessing the game, the positions form a chain of events. Every event is characterized by the ideas of the programs. The playing strength of these two program is the best the ICGA's events have seen. A most exciting moment is illustrated in Figure 7a. White played 19. exd5 and Black answered 19.... Qe5 gaining back the piece or even the rook. The decision as to which was at the discretion of White who chose the following line 20. Kf2 Qxa1 21. dxe6 fxe6 22. Bc4 Qe5. No wonder then that the game ended in a draw.
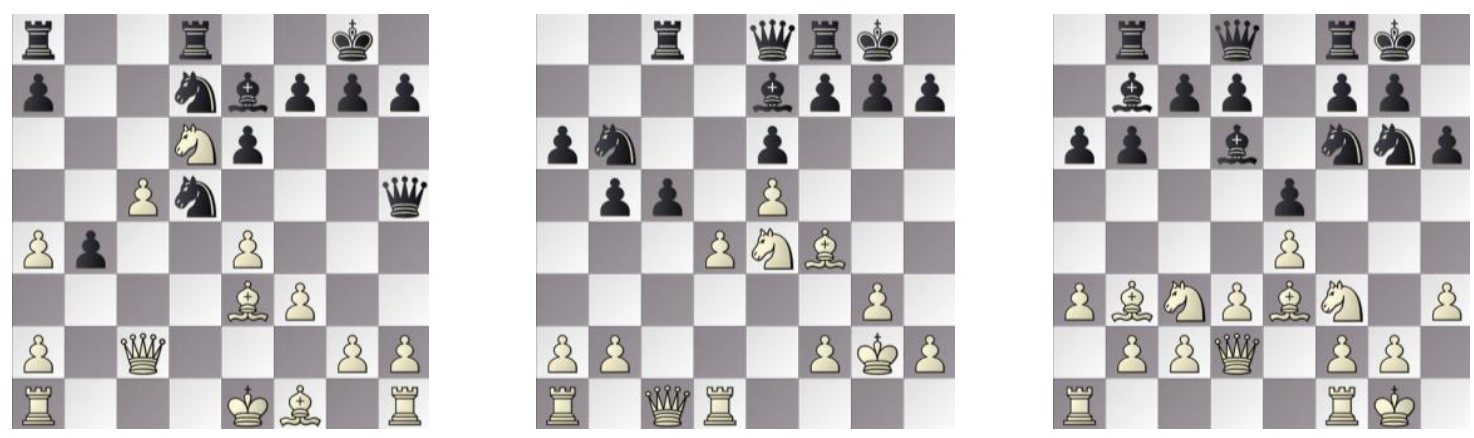

Fig. 7. R7: a) JONNY - KOMODO 19w, b) HIARCS - GINKGO 21w and c) RAPTOR - THE BARON 13w.

In its last round game HIARCS tried to improve its score by strong strategic play. Having White, the program attempted to exploit the initiative. Therefore it built up its position very carefully for the first 20 moves. However Black was on the alert and saw what White was doing. At the moment it was able to free itself, it took that opportunity by playing $20 . . . \mathbf{c 5}$, see Figure $7 \mathrm{~b}$. After the exchange of many pawns and pieces an equal ending occurred on the board. Both programs continued for a long time but the result was inevitably a draw.

The last game of the tournament was played between RAPTOR and THE BARON. Both programs wanted to complete their participation with a win. They played a quiet opening which is a rather unknown variation of the Ruy Lopez. White was able to place its pieces in excellent positions. On move 13, see Figure 7c, it saw an opportunity to sacrifice the bishop for two pawns on h6. However in its game tree, it saw that a third pawn was also coming with, in addition, some positional advantage. The latter element ensured that the piece was regained, resulting in an endgame with a pawn ahead and this was an easy win for White.

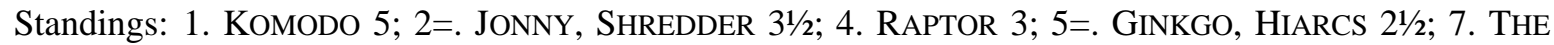
BARON 1 .

KomODO added the World Chess Software title to its World Computer Chess title. Again, our congratulations go to the KOMODO team. Given the Sonneborn-Berger tie-breaker, JONNY edged second place and HIARCS edged fifth. All results are detailed in Tables 2-4. The reduction in available parallelism in this WCSC predictably subtracted from the relative performances of JONNY, previously on 2400 cores in the WCCC, and GINKGO, previously on 224 cores.

A footnote for endgame enthusiasts. Five WCCC and eight WCSC games reached the 7-man zone: eight were drawn and five won, all by Black! Checked against the 7-man Lomonosov DTM endgame tables 
(Zakharov, 2017), no sub-8-man moves conceded any half-points but there seemed to be a premature assumption in at least three cases that it was not worth playing on, perhaps because a winning line was shown on a screen. However, programs have been known to lose the expected service of their endgame tables (Haworth, 2012). The WCCC's HIARCS - SHREDDER KQKRRP (mate in 34m), and this WCSC's THE BARON - GINKGO (KPKPPP, mate in 18) and RAPTOR - JONNY (mate in 59 and essentially KQKQP) would, in various degrees, have at least been interesting demonstrations of perfect endgame play. DTMoptimal lines from the Lomonosov EGTs have been added to the pgn records (Krabbenbos et al, 2017a/b).

Table 2

The WCSC cross-table

\begin{tabular}{|c|c|c|c|c|c|c|c|c|c|c|c|c|}
\hline \# & Program & $\mathbf{K}$ & $\mathbf{J}$ & $\mathbf{S}$ & $\mathbf{R}$ & $\mathbf{H}$ & $\mathbf{G}$ & TB & $\mathbf{W}$ & D & L Score & S-Bgr \\
\hline 1 & KOMODO & & $1 / 2$ & 1 & 1 & $1 / 2$ & 1 & 1 & 4 & 2 & 0 & 13.00 \\
\hline 2 & JONNY & $1 / 2$ & & $1 / 2$ & 1 & 0 & $1 / 2$ & 1 & 2 & 3 & $31 / 2$ & 9.50 \\
\hline 3 & SHREDDER & 0 & $1 / 2$ & & 1 & 1 & $1 / 2$ & $1 / 2$ & 2 & 3 & $31 / 2$ & 9.00 \\
\hline 4 & RAPTOR & 0 & 1 & 0 & & 1 & 1 & 1 & 3 & 3 & 0 & 6.00 \\
\hline 5 & HIARCS & $1 / 2$ & 1 & 0 & 0 & & $1 / 2$ & $1 / 2$ & 1 & 3 & $2^{1 / 2}$ & 7.75 \\
\hline 6 & GINKGO & 0 & $1 / 2$ & $1 / 2$ & 0 & $1 / 2$ & & 1 & 1 & 3 & $2^{1 / 2}$ & 5.75 \\
\hline 7 & THE BARON & 0 & 0 & $1 / 2$ & 0 & $1 / 2$ & 0 & & 0 & 2 & 4 & 3.00 \\
\hline
\end{tabular}

Tables 3 and 4

The WCSC results and progress round by round

\begin{tabular}{ccccccccc}
\hline$\#$ & Program & r1 & r2 & r3 & r4 & r5 & r6 & r7 \\
\hline $\mathbf{1}$ & KOMODO & $5 \mathrm{w}^{1 / 2}$ & $4 \mathrm{~b} 1$ & $7 \mathrm{w} 1$ & $6 \mathrm{~b} 1$ & $b y e$ & $3 \mathrm{w} 1$ & $2 \mathrm{~b}^{1 / 2}$ \\
$\mathbf{2}$ & JONNY & $3 \mathrm{~b}^{1 / 2}$ & $\mathrm{bye}$ & $5 \mathrm{w} 0$ & $4 \mathrm{~b} 1$ & $7 \mathrm{w} 1$ & $6 \mathrm{~b}^{1 / 2}$ & $1 \mathrm{w}^{1 / 2}$ \\
$\mathbf{3}$ & SHREDDER & $2 \mathrm{w}^{1 / 2}$ & $5 \mathrm{~b} 1$ & $4 \mathrm{w} 1$ & $7 \mathrm{~b} \mathrm{~b}^{1 / 2}$ & $6 \mathrm{w}^{1 / 2}$ & $1 \mathrm{~b} 0$ & $\mathrm{bye}$ \\
$\mathbf{4}$ & RAPTOR & $6 \mathrm{~b} 1$ & $1 \mathrm{w} 0$ & $3 \mathrm{~b} 0$ & $2 \mathrm{w} 0$ & $5 \mathrm{~b} 1$ & $\mathrm{bye}$ & $7 \mathrm{w} 1$ \\
$\mathbf{5}$ & HIARCS & $1 \mathrm{~b}^{1 / 2}$ & $3 \mathrm{w} 0$ & $2 \mathrm{~b} 1$ & $\mathrm{bye}$ & $4 \mathrm{w} 0$ & $7 \mathrm{~b}^{1 / 2}$ & $6 \mathrm{w}^{1 / 2}$ \\
$\mathbf{6}$ & GINKGO & $4 \mathrm{w} 0$ & $7 \mathrm{~b} 1$ & bye & $1 \mathrm{w} 0$ & $3 \mathrm{~b}^{1 / 2}$ & $2 \mathrm{w}^{1 / 2}$ & $5 \mathrm{~b}^{1 / 2}$ \\
$\mathbf{7}$ & THE BARON & bye & $6 \mathrm{w} 0$ & $1 \mathrm{~b} 0$ & $3 \mathrm{w}^{1 / 2}$ & $2 \mathrm{~b} 0$ & $5 \mathrm{w}^{1 / 2}$ & $4 \mathrm{~b} 0$ \\
\hline
\end{tabular}

\begin{tabular}{|c|c|c|c|c|c|c|}
\hline & Program & r1 r2 r3 & $\mathbf{r}^{2}$ & & & r7 \\
\hline 1 & KOMODO & $\begin{array}{lll}1 / 1 / 2 & 11 / 2 & 2^{1 / 2}\end{array}$ & $31 / 2$ & & $4 \frac{1}{2}$ & \\
\hline & JONNY & $1 / 2$ & $1 \frac{1}{2}$ & 21 & e & 31 \\
\hline 3 & SHREDDER & $1 / 2 \quad 1^{1 / 2} 2^{1 / 2}$ & 3 & & $31 / 2$ & 3 \\
\hline & RAPTOR & 1 & & 2 & 2 & \\
\hline & HIARCS & $\begin{array}{lll}1 / 2 & 1 / 2 & 11 / 2\end{array}$ & $1 \frac{1}{2}$ & $1 \frac{1}{2}$ & & 21 \\
\hline & GINKGO & 0 & 1 & $1 \frac{1}{2}$ & 2 & $2^{1 / 2}$ \\
\hline & HEBAROI & $\begin{array}{ll}0 & 0 \\
\end{array}$ & & & & \\
\hline
\end{tabular}

\section{REFERENCES}

CPW (2016a). http://preview.tinyurl.com/pez8kko. The CPW biography of Richard Pijl.

CPW (2015b). http://preview.tinyurl.com/ppnqeuz. The CPW biography of THE BARON.

Haworth, G. $M^{\mathrm{c} C}$. (2012). Chess Endgame News. ICGA Journal, 35(2), 90-93. doi:10.3233/icg-201235204

Krabbenbos, J., van den Herik, H.J. and Haworth, G.Mc C. (2016a). WCCC 2016: the 22 ${ }^{\text {nd }}$ World Computer Chess Championship. ICGA Journal, 39(1), 47-59. doi:10.3233/icg-170014. Pgn files available from http://centaur.reading.ac.uk/67922/.

Krabbenbos, J., van den Herik, H.J. and Haworth, G.M ${ }^{\mathrm{c} C}$. (2016b). WCSC 2016: the $6^{\text {th }}$ World Chess Software Championship. ICGA Journal, 39(2), 151-159. doi:10.3233/icg-170013. Pgn files available from http://centaur.reading.ac.uk/67923/.

Zakharov, V. (2016). http://tb7.chessok.com/. The query service on the 7-man MVL DTM EGTs. 